Freud: Um ciclo de leituras Silvia L. Alonso e Ana Maria S. Leal (orgs.)

Säo Paulo, Escuta

1997

\title{
O texto que insiste ou a insistência sobre Freud
}

\author{
Daniel Delouya
}

O presente livro, de um ciclo de debates em torno de textos do Freud, é uma contribuição inusitada para o leitor. Traz ao público o fruto maduro do trabalho de um grupo de analistas engajados, há pouco mais de 20 anos, em um projeto de formação cuja prática de ensino teórico foi desde sempre centrada nos textos de Freud. Não quero me deter neste momento festivo nem no convite para este - esses têm seus lugares de destaque em nossa cultura. Entretanto, o evento e o livro são certamente marcos de um freudismo no Brasil que deixou de se manifestar apenas através do que foi muitas vezes a via da contestação, da negativa - uma necessidade de marcar uma posição em relação a outros grupos dominantes - para apresentar algo que foi se construindo em seu interior. É possível que se encontre no já abastado mercado editorial brasileiro de psicanálise leituras de Freud (de autores brasileiros e estrangeiros) que talvez sejam, do ponto de vista didático, mais rigorosas, mais minuciosas e mais detalhadas do que aquelas expostas neste livro. Porém, esses trabalhos apresentados em mesas-redondas onde dois participantes comentam um certo texto de Freud e o terceiro coordena o debate que se segue - revelam uma característica única: na sua leitura, os autores descobrem e destacam os elementos na obra freudiana (refletidos no texto) que privilegiam, consciente e inconscientemente, quando tentam esboçar, na sua clínica, o desejo ou o desenho psicopatológico do paciente, a partir da transferência deste, ou quando se indagam sobre seu fazer e as modalidades complexas de operação inconsciente do aparelho psicanalítico 
(Green) que estão fadados a "conduzir". Como se o exercício da leitura fosse o meio de questionar, descobrir e aprofundar a essência do seu fazer analítico. Quero dizer que a leitura não segue a exegese de uma análise didato ou esteticofilosófica, mas pode até vir a lançar mão destes meios no diálogo vivo que trava entre um Freud incorporado no analista e o texto, o que permite enriquecer e remanejar o patrimônio psicanalítico subjetivo. Eis um freudismo consolidado! Embora este traço perpassasse a maior parte das exposições e dos debates, ele não se revela de forma igual em todos, mas salta aos olhos principalmente nas exposições de Alonso, Cromberg, Frochtengarten, M. Fuks e Menezes. São esses também, a nosso modo de ver, as pérolas preciosas deste livro.

É difícil saber se neste trajeto o encanto da primeira estação deve-se mais ao texto em questão, o livro princeps de Freud, A interpretação dos sonhos (1900), ou às belíssimas exposições das comentadoras. À parte os efeitos desses entrecruzamentos transferenciais, implicados nesta parada, os distintos enfoques - de Renata Cromberg e de Janete Frochtengarten - complementam-se um ao outro. Renata segue a ordem da construção do livro - a maneira pela qual Freud vai montando o aparelho psíquico a partir do que pôde inferir dos mecanismos e dos motivos do fenômeno onírico - para mostrar, através de recortes clínicos, como o campo transferencial é contido num semelhante aparelho onde a escuta precisa regredir às imagens - ao caráter alucinatório - do sonho da fala, nela recuperando o desejo infantil e seus desfiladeiros no sujeito. Janete diz-se fascinada pela alternância de movimentos de Freud, entre um que o compele a interpretar e a associar e outro, contrário, que pausa, que se detém frente ao desconhecido. Não nos mostra apenas esta sutil amálgama dos dois ao longo da obra, mas revela também como constituem a própria natureza do objeto: a insistência do desejo infantil exigindo a produção do sonho além de se inscrever na própria modalidade do trabalho do sonho. No entanto, o desejo, plasmado na cena infantil, nos leva ao lugar desconhecido do qual brotou - um resto, um isso indecifrável. Curiosamente, um terceiro desdobramento desta mesma amálgama se faz notar na alma do próprio texto da autora.

"Um caso de neurose obsessiva (O Homem dos ratos)" (1909), o segundo texto na ordem cronológica dos escritos de Freud deste ciclo, é tratado de forma diferente. Cleide Monteiro e Rúbia M. T. Delorenzo não se debruçam sobre o caso clínico como tal, mas preferem examinar, a partir dele, a figuração da transferência e seus prenúncios neste estágio da obra ou a configuração do superego, respectivamente. Abordagens que refletem o exercício da prática de ensino que também demanda o trabalho de síntese sobre um certo conceito, sua prefiguração e suas decorrências no desenrolar da obra. Numa fina análise, centrada nos mandatos superegóicos do paciente, Rúbia coloca em relevo as 
feições sadomasoquistas desta instância. É preciso ressaltar, no entanto, que foi a sustentação transferencial de tal economia pulsional que permitiu a Freud encontrar nesses precisos mandatos os vestígios da história do pai onde plasmouse o desejo do paciente e seu fracasso.

O estudo de Freud sobre Leonardo da Vinci (1910) é o tema de outra mesa. Nesta, Lucía B. Fuks tece observações elucidativas sobre a sublimação - um dos conceitos mais complexos em Freud - distinguindo nela o lugar das pulsões do ver (elementar) e do saber (derivada). Nas considerações sobre a criatividade e sua inibição, Lucía deixa de explorar um dos aspectos centrais do estudo de Freud sobre Leonardo - a questão do objeto, da mãe. Lacuna que vem sendo preenchida pelo fascinante estudo de Silvia L. Alonso que se utiliza deste texto de Freud para examinar o lugar da fantasia e da lembrança na análise. De um lado, inscrevem-se nelas os traços de pequenos fragmentos de cenas reais, vistos e ouvidos, desprendidos da relação com outro da infância da qual ecoam as vozes da pulsão sexual. De outro, carregam dentro delas, a temporalidade psíquica, o enriquecimento desses traços pelas retranscrições, materializando uma mistura dos tempos onde configuram-se o desejo, seu objeto e o outro deste objeto.

Na discussão sobre o texto "Luto e melancolia" (1915), Isabel D. M. Vilutis nos oferece um dos trabalhos mais coesos desta coletânea. Ela distingue, na melancolia, a identificação narcísica com o objeto cuja consequiência é a bipartição do ego onde se enuncia um conflito violento com o superego e os característicos sentimentos de culpa, o queixume e o mortífero vazio. Já a apresentação da Anna Maria Amaral desloca-se deste enfoque instancial, complementando-o ao escolher examinar, nesta afecção, o fracasso da representação. Com Winnicott, Lacan e Lambotte, ela identifica, neste fracasso, a falência do objeto de origem. Uma dobra traumática que freqüentemente leva o melancólico ao suicídio, eclipsando-se sobre a não-resposta do outro no ponto de origem, do narcisismo primário.

Miriam Chnaiderman e Mario P. Fuks comentam o texto "O estranho familiar" (1919) de formas muito distintas. Se Freud empresta do campo estético o Unheimliche, arrancando-lhe algo útil para seu terreno, o trabalho de Miriam, assim como o debate que o segue, exibem a irresistível atração da sua original morada. No caminho da linguagem à temporalidade, a autora nos oferece uma análise rica que se centra, no entanto, no plano fenomenológico da vivência. Já o trabalho de Mario acompanha Freud quando discorre, numa notável sensibilidade imaginativa, sobre o conto de Hoffmann, "O homem da areia" (1817). Resgata e acentua no Unheimliche os recursos "defensivos" do eu, como a recusa e a rejeição, situando-os em relação aos do recalque, articulando-os com o complexo do castração e seus protagonistas - o pai e a mãe do herói.

Se Mario recoloca em cena a instância que foi, durante muito tempo, odiada no meio freudiano ("le moi haïssable"), Alcimar A. S. Lima aproxima-se, em seus comentários sobre "Além do princípio do prazer" (1920), de uma aborda- 


\section{RESENHAS}

gem que insiste em ignorar a origem e o foro instancial do eu. Ao aroma e o hom gosto da contribuição estética na apreensão do irrepresentável (de Miriam), o autor nos acrescenta - fascinado - a voz respeitável de cientistas que têm buscado lucrar nos campos do saber sobre o social. Criativo, tenta nos convencer em incorporar este novo ruído - este caos - à nossa ordem. Temo que a força explicativa do conceito deleuziano de acontecimento não faz outra coisa senão desviar a atenção do trabalho que nos demandam as ricas ligações que Freud estabelece, neste texto, entre o influxo traumático, a pulsão de morte e as pulsões do eu. É nesta perspectiva, sobre o eu, e oposta à do Alcimar, que Luís C. Menezes aborda, a partir do texto de Freud, o desafio técnico com que se depara o analista na escuta das violências feitas ao eu de um número cada vez maior de pacientes que chegam aos nossos consultórios. É preciso nesses casos, mais do que em outros, se dispor a escutar, por um bom tempo, antes de decidir fazer para que algo aconteça. Na sua leitura de Freud, Menezes alcança um horizonte maior do que os demais artigos do livro.

Embora seja o texto mais curto de Freud, os comentários da Ana M. Sigal sobre "A organização genital infantil" (1923) são dos mais extensos do livro, o que não deixa de ser autofigurativo da problemática do falo: um menor, motivo de toda a diferença! Maria Aparecida K. Aidar se debruça sobre o texto "Consequiências psíquicas da diferença anatômica" (1925), associado à mesma problemática. Onde a primeira se estende, com muita habilidade, sobre o alcance do texto - se bem que mais na vertente de Lacan-Laplanche (veja a ressignificação) do que permite a nota de Freud - a segunda afunila em direção ao que acaba sendo, afinal, seu alvo comum: a espinhosa questão sobre a feminilidade. Um ar de contestação não escapa ao ouvinte e ao leitor. "Cheias de dedos" para com Freud, os excessivos elogios mal conseguem encobrir o "osso indigesto" que estes textos lhes colocam. Diante de tais atitudes contrastantes não surpreende que o conceito da recusa, central a esses textos, acabe sendo ignorado. Com meias vozes as duas se opõem - é preciso que se diga isto - à articulação de Freud da feminilidade em torno do falo, apoiando-se, tímidas, nas miragens dos "novos paradigmas" (a positividade dos buracos negros) ou da limitação que o tempo de Freud lhe colocava (não pôde prever a participação da mulher na sociedade). Em nenhum outro lugar evidencia-se, com tamanha força, o embate transferencial do analista com o texto de Freud, demonstrando, neste caso, o que Cida ressalta com tanta propriedade ao dizer que a mulher tem mais dificuldade em esconder a sua bissexualidade do que o homem.

Resenhar uma coletânea de trabalhos é tarefa freqüentemente ingrata. Porém, ter assistido ao evento e participado, de certo modo, de seus bastidores, da longa história do qual é efeito, as diferentes leituras no livro e os debates que as acompanham, constituem, para mim, uma saborosa memória-fonte. Num convite à leitura - ainda mais esta - é difícil manter a imparcialidade. 